\title{
Connexin-43 gap junctions are involved in multiconnexin-expressing stromal support of hemopoietic progenitors and stem cells
}

Jose A. Cancelas, Wendy L. M. Koevoet, Alexandra E. de Koning, Angelique E. M. Mayen, Elwin J. C. Rombouts, and Rob E. Ploemacher

\begin{abstract}
Gap junctions (GJs) provide for a unique system of intercellular communication (IC) allowing rapid transport of small molecules from cell to cell. GJs are formed by a large family of proteins named connexins (Cxs). Cx43 has been considered as the predominantly expressed $\mathrm{Cx}$ by hematopoietic-supporting stroma. To investigate the role of the $\mathrm{Cx}$ family in hemopoiesis, we analyzed the expression of $\mathbf{1 1}$ different $\mathrm{Cx}$ species in different stromal cell lines derived from murine bone marrow (BM) or fetal liver (FL). We found that up to $5 \mathrm{Cxs}$ are
\end{abstract}

expressed in FL stromal cells (Cx43, Cx45, Cx30.3, Cx31, and Cx31.1), whereas only Cx43, Cx45, and Cx31 were clearly detectable in BM stromal cells. In vivo, the Cx43-deficient 14.5- to 15-day FL cobblestone area-forming cells (CAFC)week 1-4 and colony-forming unit contents were $26 \%-38 \%$ and $39 \%-47 \%$ lower than in their wild-type counterparts, respectively. The reintroduction of the Cx43 gene into Cx43-deficient FL stromal cells was able to restore their diminished IC to the level of the wild-type FL stromal cells. In addition, these Cx43-reintroduced stro- mal cells showed an increased support ability (3.7-fold) for CAFC-week 1 in normal mouse BM and 5-fold higher supportive ability for CAFC-week 4 in 5-fluorouracil-treated BM cells as compared with Cx43-deficient FL stromal cells. These findings suggest that stromal Cx43-mediated IC, although not responsible for all GJ-mediated IC of stromal cells, plays a role in the supportive ability for hemopoietic progenitors and stem cells. (Blood. 2000;96:498-505)

(1) 2000 by The American Society of Hematology

\section{Introduction}

Mature blood cells are derived from undifferentiated stem and progenitor cells in a highly complex series of maturational and divisional steps that occur in different tissues during embryonic development. The microenvironment seems to be an important factor influencing the proliferative activity and differentiation process of the stem and progenitor cells by local positive and negative signaling to the target cells. ${ }^{1}$ The following 3 mechanisms can be assumed to mediate the regulation of proliferation and differentiation of hematopoietic stem cells by stromal cells ${ }^{2}$ : $(a)$ by cytokine receptor-ligand interaction, $(b)$ by interaction of adhesion molecules on hemopoietic cells with stromal cells or the extracellular matrix, or $(c)$ by direct cell-to-cell communication between stromal cells or between stromal cells and hemopoietic cells.

Very little is known about the regulatory mechanisms of direct cell-to-cell communication in the hematopoietic microenvironment. Intercellular gap junctions (GJs) represent the most wellknown intercellular communication (IC) system, and they are characterized by the existence of plaques of narrow channels between contacting cells. Each channel is formed by 2 hemichannels or hemiconnexons, and each one of them is contributed by 1 of the 2 adjacent cells. A hemiconnexon is an oligomeric assembly of 6 polypeptide subunits, or connexins (Cxs). Different tissuespecific Cxs have been characterized and cloned. ${ }^{3}$ These proteins are highly homologous and encoded by at least 4 gene subfamilies $(\alpha, \beta, \gamma \text {, and } \delta)^{4,5}$ that include 15 different Cxs in rodents. According to their molecular weight, they have been named $\mathrm{Cx} 26$, Cx30, Cx30.3, Cx31, Cx31.1, Cx32, Cx33, Cx36, Cx37, Сx40,
Cx43, Cx45, Cx46, Cx50, and Cx57. These channels form the only known system for direct diffusional exchange of ions and small molecules (ie, molecular weight $<1000$ ) between contacting cells. ${ }^{6}$ Nutrients and second messengers can be quickly transported in this way through cell communication networks.

There are few reports analyzing the GJs in hematopoietic tissues. By analysis of lucifer yellow (LY) dye transfer in a hemopoiesis-supporting bone marrow (BM) stromal cell line, Dorshkind et $\mathrm{al}^{7}$ showed the presence of Cx43-type GJ-IC that was inhibited by interleukin-1. Rosendaal et $\mathrm{al}^{8}$ reported on the basis of immunohistological studies that, in adult mouse BM, the Cx43 GJ epitopes are rare but up-regulated 80 - to 100 -fold in the marrow of the neonate or after forced stem cell division (by administering 5-fluorouracil [5-FU] or irradiation). This up-regulation occurred soon after the insult, before recognizable blood cells formed, and around the time at which primitive stem cells were triggered to go into cycle, suggesting the presence of a latent network of GJs in normal hemopoietic tissues. Our group ${ }^{9}$ has previously reported that the global blockade of all GJ-IC by amphotericin B reversibly inhibited the cobblestone area (CA) formation and hemopoiesis in stroma-containing cultures.

Strong evidence supports that more than $1 \mathrm{Cx}$ gene is expressed in many specific tissues or cells. This fact suggests that different GJ proteins are allowing the permeability of different molecules. In osteoblasts ${ }^{10,11}$ and in fetal fibroblasts, ${ }^{12}$ it has been shown that different GJ proteins create channels with different conductance
From the Department of Hematology, Faculty of Medicine, Erasmus University of Rotterdam, The Netherlands.

Submitted August 23, 1999; accepted March 13, 2000.

Supported by a fellowship grant (J.A.C.) from Fundacion Areces, Madrid, Spain.

Reprints: Rob E. Ploemacher, Dept of Hematology, Faculty of Medicine,
Erasmus University, Dr Molewaterplein 50, 3015 GE Rotterdam, The Netherlands; e-mail: ploemacher@hema.fgg.eur.nl.

The publication costs of this article were defrayed in part by page charge payment. Therefore, and solely to indicate this fact, this article is hereby marked "advertisement" in accordance with 18 U.S.C. section 1734.

(c) 2000 by The American Society of Hematology 
properties. This finding could suggest that their regulatory cell functions might also differ among them.

We conducted our efforts to study whether other Cxs, in addition to $\mathrm{Cx} 43$, are expressed by hemopoiesis-supporting stromal cells and whether stromal Cx43-dependent GJ-IC may influence hemopoiesis in vivo and in vitro in stroma-supported longterm culture.

\section{Materials and methods}

\section{Fetal liver and BM cells obtention}

Heterozygous C57B1/6-Gja-1 ${ }^{\mathrm{tm} 1 \mathrm{Kdr}}$ mice $^{13}$ were housed under specified pathogen-free conditions and supplied with standard pellet food and water ad libitum. Mice were mated to produce Cx43 knockout (KO) embryos. Females were scored daily for the presence of the vaginal plug characteristic of the beginning of pregnancy. Day 0 of pregnancy was defined as the day of plug discovery (day 0 postcoitum) and the fetal specimens aged accordingly. Pregnant females were killed by cervical dislocation on day 14.5-15 of pregnancy, and the fetuses were removed through an anterior abdominal incision. After individual fetuses were isolated, fetal livers (FLs) and tails were carefully dissected to avoid contamination of surrounding tissues and were processed separately. Tails were used for $\mathrm{Cx} 43$ gene typing purposes. FL cells were suspended by pipetting the tissue several times in a medium consisting of calcium/magnesium-free phosphate-buffered saline (PBS; Gibco, Breda, The Netherlands), bovine serum albumin 0.5\% (BSA; Sigma, St. Louis, MO), and sodium azide 0.01\% (Merck, Darmstad, Germany; PBS/BSA/NaN ${ }_{3}$ buffer), which has been shown to maintain hematopoietic progenitors for $24-48$ hours, ${ }^{14}$ until tail genotyping was finished $(<16$ hours).

C57/B16, 10- to 15-week-old mice (from the Experimental Animal Facility, Erasmus University of Rotterdam, The Netherlands) were kept in the same conditions as mentioned above. In each experiment, 3-5 mice were intravenously injected with $150 \mathrm{mg} / \mathrm{kg}$ body weight 5 -FU (Sigma) on day 0 . Femoral BM was harvested on day +6 postinjection from normal and treated mice.

\section{Stromal cell lines}

We used 4 BM-derived stromal cell lines (FBMD-1, NBM11F4G, NBM11F10H, and NBM6D3D) and 4 FL-derived stromal cell lines (FL1E2C, FL7H7B, FLB6-1, which are all wild type (wt) for Cx43 gene-Cx43-wt cell lines-and FLB6-2 from Cx43-KO mice- $\mathrm{Cx} 43^{-}$cell line). Except for the FBMD-1, FLB6-1, and FLB6-2 cell lines, the lines were cloned by limiting dilution and obtained from Dr T. Ghayur (BASF, Worcester, MA). Previously, we described that the FBMD-1, NBM11F4G, NBM11F10H, NBM6D3D, FL1E2C, and FL7H7B cell lines are able to support hemopoiesis in vitro and their differences in GJ-IC abilities, as assessed by LY dye transfer., 915 The FLB6-1 and FLB6-2 stromal cell lines were developed by culturing cell explants from $\mathrm{Cx} 43-$ wt and $\mathrm{Cx} 43-\mathrm{KO}$ day $15 \mathrm{FL}$ from C57/B16-Gja $1^{\mathrm{tm} 1 \mathrm{Kdr}}$ mice, respectively. Genotyping for identification of homozygous mice was done by standard polymerase chain reaction (PCR) technique by using primers addressed to neomycinphosphotransferase and $\mathrm{Cx} 43$ genes as previously described. ${ }^{16}$ Cell explants were cultured in T25 tissue-culture flasks (Costar, Corning, NY) at $33^{\circ} \mathrm{C}$ and $10 \% \mathrm{CO}_{2}$. Culture medium contained IMDM, glutamax 5 $\mathrm{mmol} / \mathrm{L}, 100 \mathrm{IU} / \mathrm{mL}$ penicillin, $0.1 \mathrm{mg} / \mathrm{mL}$ streptomycin (all from Gibco), $20 \%$ fetal calf serum (FCS; optimal batch for fibroblast-like cell growth; Hyclone Laboratories Inc., Logan, UT), $10 \mu \mathrm{mol} / \mathrm{L}$ hydrocortisone (hydrocortisone-21-hemisuccinate sodium salt; Sigma), and $100 \mu \mathrm{mol} / \mathrm{L} \beta$-mercaptoethanol (Merck). Every 2 days, all medium was harvested and centrifuged, and a 1:1 mixture of conditioned medium and fresh medium was reinoculated into the T25 flasks. Clusters of adherent cells were rapidly seen after 2-4 days of culture. Adherent cells were trypsinized, and cells were submitted to at least 15 passages to be certain that they did not contain any hematological growth. These conditions strongly favor the outgrowth of fibroblastic cells. Once the cell lines were established, they were grown in a medium containing IMDM, 10\% FCS, 5\% horse serum, $100 \mathrm{IU} / \mathrm{mL}$ penicillin, $0.1 \mathrm{mg} / \mathrm{mL}$ streptomycin, and $10 \mu \mathrm{mol} / \mathrm{L} \beta$-mercaptoethanol (stromal cell medium) at $33^{\circ} \mathrm{C}$ and $10 \% \mathrm{CO}_{2}$. Cell lines were used for stromal support when fully confluent and between passages 15 and 21 .

FLB6-1 showed spindle-shaped cells with thin, long cytoplasmic prolongations. These cells displayed contact inhibition, and their growth rate was similar to our BM reference stromal cell line FBMD-1. Phenotypic analysis of the FLB6-1 cell line showed positivity for Ly6A/E, CD34, and Ly6C but no membrane expression of CD3, B220, Mac-1, Gr-1, Thy-1, c-kit, or PECAM-1/CD31. The Cx43-KO cells (FLB6-2) present many short cytoplasmic prolongations, and they grew faster and at higher saturation density than the $\mathrm{Cx} 43$-wt stromal cells. $\mathrm{Cx} 43-\mathrm{KO}$ cells showed the same immunophenotype as $\mathrm{Cx} 43$-wt FL stromal cells.

\section{Reintroduction of the Cx43 gene into Cx43-KO FL-derived stromal cells}

We used the packaging cell line PA317/pBABECx43a (kindly provided by Dr Warn-Cramer and Dr Lau, University of Hawaii at Manoa, Honolulu, $\mathrm{HI}$ ) because of its ability to reintroduce the $\mathrm{Cx} 43$ gene into mouse Cx43-deficient fibroblasts. ${ }^{12}$ The vector inserted in this cell line is the pBABECx $43 \mathrm{a}$, composed of the fragment $\mathrm{G} 2$ of the rat $\mathrm{Cx} 43$ gene as reported by Beyer et al, ${ }^{17}$ preceded by a $5^{\prime}$-LTR and a gag region and followed by a SV40 promoter that regulates the expression of the puromycin resistance gene. The cell line PA317/pBABECx43a was grown at $37^{\circ} \mathrm{C}, 5 \% \mathrm{CO}_{2}$ in IMDM supplemented with $10 \%$ newborn calf serum, $100 \mathrm{IU} / \mathrm{mL}$ penicillin, $0.1 \mathrm{mg} / \mathrm{mL}$ streptomycin, and $7 \mu \mathrm{g} / \mathrm{mL}$ puromycin (Sigma) until $80 \%$ confluency. At that time, medium was changed for stromal cell medium with no puromycin. After 24 hours, supernatant was harvested and passed through a $0.45-\mu \mathrm{m}$ mesh filter. Filtered retroviral supernatant was added to $10 \%-20 \%$ confluent passage 14 Cx43-KO FL stromal cells. Three successive daily incubations were performed in the same way until target cells reached $90 \%$ confluency. Thirty-six hours after starting the last cycle of incubation of target cells with the retroviral supernatant, medium was changed for stromal cell medium containing 7-10 $\mu \mathrm{g} / \mathrm{mL}$ puromycin. Two cell lines were developed: FLB6-3 and FLB6-4 $\left(\mathrm{Cx}_{43}{ }^{+}\right.$cell lines). Transduced cells were passed for 7 additional passages to passage 21 with medium containing puromycin to maintain the transduced cells.

\section{Calcein dye transfer among stromal cells}

Calcein dye coupling of stromal cells was analyzed according to Ziambaras et al, ${ }^{18}$ with some modifications. Confluent stromal cells were trypsinized and incubated with $5 \mu \mathrm{mol} / \mathrm{L}$ calcein-AM (Molecular Probes, Leiden, The Netherlands) for 30 minutes at $37^{\circ} \mathrm{C}$. Cells were washed for 4 times in $\mathrm{Ca}^{++} / \mathrm{Mg}^{2+}$-containing Hanks balanced salted solution and passed through a $70-\mu \mathrm{m}$ mesh filter. After that, 50 cells (in $0.5 \mathrm{~mL}$ stromal medium) were cocultured in each of $32-\mathrm{cm}^{2}$ wells containing a pregrown homocellular confluent layer of stromal cells (around 40000 cells per well). Wells were examined after 2 hours of coculture under an inverted fluorescent microscope. A positive event of GJ-IC was considered when a cluster of 2 or more neighboring cells was observed. A negative communicating event was considered when a single fluorescent cell was seen. The percentage of positive events and the number of fluorescent cells per cluster was recorded. Control incubation of stromal cells with $5 \mu \mathrm{mol} / \mathrm{L}$ calcein did not produce similar clusters, and it only increased background fluorescence in peripheral cells close to the edge of the well.

\section{Immunofluorescence analysis for $\mathrm{Cx}$ proteins}

Stromal cells were plated in culture chambers (Lab-Tek, Chamber Slide, Nunc, Naperville, IL) and grown overnight in stromal cell medium. After harvesting medium, slides were washed with PBS twice and fixed in ice-cold methanol for 30 minutes. After fixation, cells were permeabilized in $1 \%$ Triton-X-100, washed with PBS, and then incubated for 1 hour at room temperature in $\mathrm{PBS} / 10 \%$ mouse serum containing the polyclonal rabbit antiserum directed against $\mathrm{Cx}_{43} 3^{17}$ (1:70; Zymed, South San Francisco, CA), $\mathrm{Cx}_{4} 5^{19}$ (1:150; Chemicon International, Temecula, CA), and $\mathrm{Cx} 31^{20}(1: 150$; a small aliquot was kindly provided by Prof K. Willecke, 
University of Bonn, Germany). All of the antisera are able to recognize specific intracellular carboxy-terminal domains of the mentioned $\mathrm{Cx}$ proteins. After washing the slides, they were incubated with goat anti-rabbit FITC conjugate (Sigma) for 1 hour in the dark. After additional washing steps, the slides were mounted in Vectashield medium (Vector Laboratories, Burlingame, CA) and visualized by epifluorescence light microscopy.

\section{Western blot assay for membrane-bound Cx43 expression}

Flasks containing confluent cells were briefly rinsed with cold calcium/ magnesium-free PBS and then lysed directly by addition of ice-cold alkaline buffer, containing $2 \mathrm{mmol} / \mathrm{L} \mathrm{NaHCO}, 20 \mathrm{mmol} / \mathrm{L} \mathrm{NaOH}, 5$ $\mathrm{mmol} / \mathrm{L}$ EDTA and protease inhibitor Complete (Boehringer Mannheim, Mannheim, Germany) according to manufacturer's instructions. The lysate was sheared by serial passage through a 25 -gauge needle and further homogenized by serial cycles of freezing and thawing. Protein concentration was determined by BCA protein assay (Pierce, Rockford, IL). The insoluble fragments enriched for membrane-bound $\mathrm{Cx} 43$ were collected after centrifugation for 60 minutes at $55000 \mathrm{rpm}$ at $4^{\circ} \mathrm{C}$, resuspended in Laemmli buffer, and stored at $-20^{\circ} \mathrm{C}$ until use.

Original protein $(100 \mu \mathrm{g})$ was separated by SDS-PAGE (10\% polyacrylamide) and transferred onto a nitrocellulose membrane (Protran BA83, Schleicher \& Schuell, Dassel, Germany) by electroblotting. The membrane was incubated for 2 hours in 5\% nonfat dry milk powder (Biorad, Veenendaal, The Netherlands) in PBS/0.1\% Tween-20 (Sigma) for blocking nonspecific sites, rinsed in PBS, and incubated overnight with the polyclonal antibody anti-Cx43 (Zymed; 1:250) in PBS/10\% FCS/0.1\% Tween20 . The membrane was then washed 4 times with PBS/10\% FCS $/ 0.1 \%$ Tween-20 and incubated with a secondary antibody (antirabbit immunoglobulin horseradish peroxidase conjugate; 1:3000), and the bands were visualized with a chemoluminescence detection system according to manufacturer's instructions (ECL, Amersham-Pharmacia Biotech, Rainham, UK).

\section{Reverse transcription (RT)-PCR}

Monolayer confluent cell lines were lysed with Trizol (Life Technologies, Grand Island, NY) according to the manufacturer's instructions. RNA concentration was determined spectrophotometrically at $260 \mathrm{~nm}$ as previously described. ${ }^{21}$ RNAse inhibitor (120 IU) was added per $10 \mu \mathrm{g}$ RNA, and RNAs were frozen at $-80^{\circ} \mathrm{C}$ until use. In our experience, contaminating genomic DNA was still present in most samples. For that reason, we used a technique based on the use of $\mathrm{Mn}^{2+}$-DNAse to degrade contaminating genomic DNA, ${ }^{22}$ with some modifications. Briefly, a first 30-minute

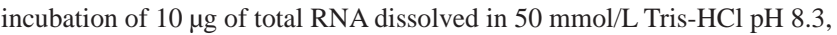
$75 \mathrm{mmol} / \mathrm{L} \mathrm{KCl}, 3 \mathrm{mmol} / \mathrm{L} \mathrm{MgCl}_{2}, 5 \mathrm{mmol} / \mathrm{L} \mathrm{MnCl}_{2}, 50 \mathrm{pg}$ rabbit $\alpha$-globin messenger RNA (mRNA; $90 \%$ purity; Gibco BRL) as an internal standard, and 5 IU RNAse-free DNAse I (Boehringer Mannheim) (total volume, 20 $\mu \mathrm{L}$ ) was performed at $37^{\circ} \mathrm{C}$. The reaction was stopped by heating at $70^{\circ} \mathrm{C}$ for 10 minutes, and the mix was split into $2(-\mathrm{RT}$ and $+\mathrm{RT})$ tubes. A $10-\mu \mathrm{L}$ solution containing oligo $(\mathrm{dT})_{12-18}$ as a random primer (Pharmacia Biotech; final concentration: $100 \mu \mathrm{mol} / \mathrm{L}$ ), dithiothreitol (Life Technologies; final concentration: $10 \mathrm{mmol} / \mathrm{L}$ ), and each of the 4 dNTPs (Pharmacia Biotech; final concentration of each: $125 \mu \mathrm{mol} / \mathrm{L}$ ) diluted in the same RT buffer were added. After 5 additional minutes at $72^{\circ} \mathrm{C}, 5$ IU RT SuperScript Rnase $\mathrm{H}^{-}$ (Gibco BRL) was exclusively added to the $+\mathrm{RT}$ tubes. The reaction mixtures were incubated at $37^{\circ} \mathrm{C}$ during 90 minutes and at $92^{\circ} \mathrm{C}$ during 10 minutes for enzyme inactivation. Complementary DNAs (cDNAs) were used immediately or kept at $-80^{\circ} \mathrm{C}$ until use.

cDNA aliquots corresponding to $0.25 \mu \mathrm{g}$ of total RNA from the cell lines and $2.5 \mathrm{pg}$ rabbit $\alpha$-globin mRNA were amplified by using specific primers for $11 \mathrm{Cx}_{\text {genes }}{ }^{23}$ and for the gene of hypoxanthine phosphoribosyltransferase (HPRT) (primers were 5'-GTAATGATCAGTCAACGGGGGAC-3' and 3'-ACCAATTCCAACGTTCGAACGACC-5'; amplicon length: 179) as a housekeeping gene. Every PCR tube contained $10 \mathrm{mmol} / \mathrm{L}$ Tris- $\mathrm{HCl}, 50 \mathrm{mmol} / \mathrm{L} \mathrm{KCl}, 1.5 \mathrm{mmol} / \mathrm{L} \mathrm{MgCl}_{2}, \mathrm{pH} 8.3 ; 240$ mol//L dNTPs; $50 \mathrm{pmol}$ of each primer of $5^{\prime}$-and $3^{\prime}$-Cx primers, $5^{\prime}$-rabbit $\alpha$-globin and $3^{\prime}$-rabbit $\alpha$-globin primers; and 1 unit of Taq DNA polymerase (SuperTaq, Sphaero-Q, Leiden, The Netherlands). The reactions were performed by using a touchdown protocol ${ }^{23}$ for 35 cycles. Control -RT tubes were always run in parallel. PCR products were incubated with the fluorescent dye Sybr-Green (Molecular Probes) and electrophoresed in a 2\% agarose gel. Amplified DNA products were exposed to UV light, and green fluorescent-emitted light image was digitalized and recorded. Semiquantitative analyses were performed by determining the mean density ratio between the $\mathrm{Cx}$ and the rabbit $\alpha$-globin bands in the PCR products of 3 2 -fold serial dilutions of the cDNA.

\section{Cobblestone area-forming cell assay}

Cobblestone area-forming cell (CAFC) frequency analysis was performed as described previously. ${ }^{24}$ Stromal layers were prepared using the FBMD$1,{ }^{15} \mathrm{Cx} 43^{-}$(FLB6-2), and Cx43+ (FLB6-3 and FLB6-4) FL stromal cell lines. FBMD-1 cells were used between passages 16 and 20, FLB6-2 cells were used at passage 21 , and the $\mathrm{Cx} 43^{+}$cell lines at passage +7 after the transduction (final passage 21). Flat-bottom 96-well plates (Falcon, Lincoln Park, NJ) were inoculated with $10^{3}$ stromal cells per well from logarithmic phase cultures. Culture plastics destined for establishment of stromal feeders were incubated at $4{ }^{\circ} \mathrm{C}$ overnight with $0.3 \%$ porcine gelatin (Sigma) in Milli-Q water to improve adherence of the stromal layer for up to 6 weeks. Except for the FBMD-1 cell line, the cell lines were irradiated to prevent overgrowth of the cells after reaching confluency. It has been demonstrated previously that BM stromal cell gap-junctional communication is resistant to irradiation in vitro. ${ }^{25} \mathrm{FL}$ stromal cells were irradiated at 40 Gy delivered by a ${ }^{137} \mathrm{Cs}$ source (Gammacell, Atomic Energy of Canada, Ottawa, Canada), 18-24 hours before inoculation. Suspensions of normal $\mathrm{BM}$ cells were overlaid on these stromal layers in 12 dilutions, 2-fold apart, consisting of 15 wells per dilution to allow limiting dilution analysis of the precursor cells forming hemopoietic clones under the stromal layer. Cultures were fed weekly by changing half of the medium and frequencies of CAFC determined at weekly intervals (CAFC-week 1 to CAFC-week 6). Wells were scored positive if at least one phase-dark hematopoietic clone (CA, containing 5 or more cells) was seen. The frequency of CAFC was then calculated by using Poisson statistics as described previously. ${ }^{26}$

\section{Colony-forming cell assay}

FL cells $\left(5 \times 10^{4}\right.$ and $\left.10^{5}\right)$ were plated for quantification of colony-forming unit granulocyte-macrophage (CFU-GM) and burst-forming unit erythroid (BFU-E) in a semisolid (0.88\% methylcellulose; Methocel, Stade, Germany) culture medium (CellGro SCGM, Boehringer Ingelheim Bioproducts, Heidelberg, Germany). The erythroid cultures contained 30\% FCS, $10 \%$ hemin (Sigma), $10 \mathrm{U} / \mathrm{mL}$ rh-erythropoietin (Jansen-Cilag, Tilburg, The Netherlands), and $50 \mathrm{ng} / \mathrm{mL} \mathrm{rm}-\mathrm{SCF}$ (kindly provided by Genetics Institute, Cambridge, MA). Colonies were scored after 10 days of culture at $37^{\circ} \mathrm{C}$ and $10 \% \mathrm{CO}_{2}$.

\section{Statistical analysis}

Results are expressed as mean \pm standard deviation except when otherwise stated. Baseline comparisons used Mann-Whitney $U$ test for 2 independent samples, Kruskal-Wallis test for 3 or more independent samples, or Wilcoxon signed rank test for paired data. Statistical significance threshold was established at $P<.05$.

\section{Results}

\section{Cx gene expression}

To characterize the $\mathrm{Cx}$ species expressed by stromal cells, we analyzed 4 BM-derived and 4 FL-derived cell lines able to support hemopoiesis in vitro. Of $11 \mathrm{Cx}$ genes that we analyzed for mRNA transcription by RT-PCR, the expression of Cx26, Cx32, Cx37, Cx40, Cx46, and Cx50 was undetectable.

Figure 1 shows the expression of Cx30.3, Cx31, Cx31.1, Cx43, and $\mathrm{Cx} 45$ by RT-PCR. Cx45 was expressed by all of the cell lines. 


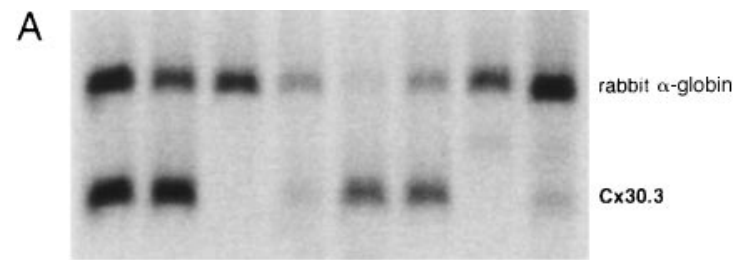

B

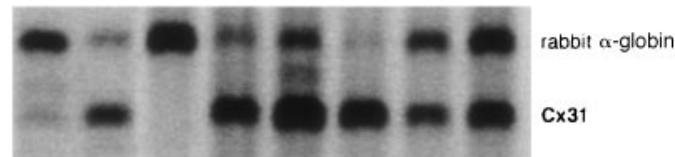

C

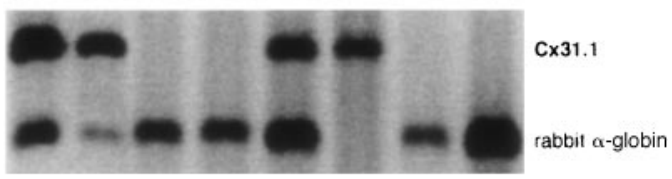

D

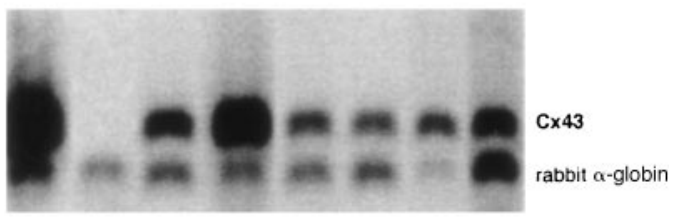

$E$

E

$\mathrm{F}$

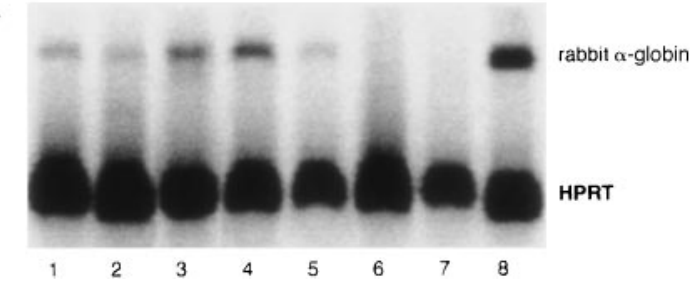

Figure 1. Semiquantitative Cx mRNA expression in stromal cell lines. The experiment shows the expression of Cx30.3 (182 bp, A), Cx31 (182 bp, B), Cx31.1 (357 bp, C), Cx43 (294 bp, D), and Cx45 (444 bp, E) in 8 different stromal cell lines. Rabbit $\alpha$-globin was used as an internal standard (257 bp). HPRT was used as a housekeeping control gene (179 bp, F). Analyses were performed at least twice. Lane 1, FLB6-1; lane 2, FLB6-2; lane 3, FBMD-1; lane 4, NBM11F4G; lane 5, FL1E2C; lane 6, FL7H7B; lane 7, NBM11F10H; and lane 8, NBM6D3D.

Cx43 was expressed by all of them except Cx43- (FLB6-2) cells as expected. Cx30.3 and Cx31 were expressed by all FL cell lines and faintly by NBM11F10H and NBM6D3D. Cx31 was expressed by all cell lines except the BM stromal cell line FBMD-1. By semiquantitative analysis of sets of 3 serial 2-fold dilutions of cDNA, we were not able to consistently observe any significant compensation in the expression of $\mathrm{Cx} 45, \mathrm{Cx} 30.3, \mathrm{Cx} 31$, or $\mathrm{Cx} 31.1$ in the $\mathrm{Cx} 43^{-}$cell line with respect to all the $\mathrm{Cx} 43$-wt FL cell lines (data not shown).

In addition, by using appropriate antibodies with known specificity, we studied the protein expression of 3 different $\mathrm{Cx}$ gene products $(\mathrm{Cx} 43, \mathrm{Cx} 45$, and $\mathrm{Cx} 31)$ that were transcribed in both $\mathrm{BM}$ and FL cell lines. As observed by immunofluorescence, the expression of $\mathrm{Cx} 43$ was present in both $\mathrm{BM}$ and FL cell lines, but the expression pattern was different among cell lines (Table 1). In general, the plasma membrane showed most of the $\mathrm{Cx} 43$ expres-
Table 1. Connexin protein expression as assessed by immunofluorescence in 8 different stromal cell lines

\begin{tabular}{|c|c|c|c|c|c|c|}
\hline & \multicolumn{2}{|c|}{ Cx43 } & \multicolumn{2}{|c|}{ Cx45 } & \multicolumn{2}{|c|}{$\mathrm{C} \times 31$} \\
\hline & Membrane & Cytoplasm & Membrane & Cytoplasm & Membrane & Cytoplasm \\
\hline FBMD-1 & ++ & \pm & + & - & n.d. & n.d. \\
\hline NBM11F4G & ++ & + & + & + & n.d. & n.d. \\
\hline NBM11F10H & + & + & ++ & ++ & n.d. & n.d. \\
\hline NBM6D3D & ++ & ++ & + & + & n.d. & n.d. \\
\hline FL1E2C & \pm & \pm & ++ & + & n.d. & n.d. \\
\hline FL7H7B & \pm & \pm & + & + & n.d. & n.d. \\
\hline $\begin{array}{l}\text { FLB6-1 } \\
\text { (Cx43-wt) }\end{array}$ & ++ & + & + & + & + & + \\
\hline $\begin{array}{l}\text { FLB6-2 } \\
\quad(\mathrm{C} \times 43-\mathrm{KO})\end{array}$ & - & - & + & + & + & + \\
\hline $\begin{array}{l}\text { FLB6-3 } \\
\text { (Cx43 reintr.) }\end{array}$ & + & \pm & + & + & + & + \\
\hline
\end{tabular}

++ , high expression; +, intermediate expression; \pm , weak expression; -, no expression; n.d., not done; Cx, connexin; wt, wild type; KO, knockout; reintr., reintroduced.

sion (Figure 2). This expression was frequently at the most distal points of the cell extensions, probably in regions of cell-cell contact. Cx expression on the membrane was either in a punctate way or more frequently as thick fluorescent spots, which could represent gap junctional plaques of varying size. In addition, FLB6-1 cells expressed a large amount of protein in the perinuclear/ nuclear area with frequently brighter locations, suggesting large $\mathrm{Cx} 43$ protein pools destined to be readily expressed in the outer membrane. FL1E2C and FL7H7B cell lines also expressed Cx43 protein in either cell membrane or cytoplasm but at lower intensity as compared with FLB6-1, FBMD-1, and NBM6D3D (which had the highest level of expression). As expected, the fluorescence in FLB6-2 (Cx43-KO) cells for Cx43 staining was similarly faint as that found in the isotypic control.

Immunolocalization of $\mathrm{Cx} 43$ in transduced cells demonstrated punctate staining of $\mathrm{Cx} 43$ in long cellular extensions and in regions of the plasma membrane (Figure 3A). However, as compared with Cx43-wt FL stromal cells, Cx43-reintroduced FL cells showed a fainter expression in their membranes and a more diffuse cytoplasmic fluorescent pattern. We quantitated the total $\mathrm{Cx} 43$ protein by immunoblot analysis of $\mathrm{Cx} 43^{+}$cell lines, revealing a reactive band with a molecular weight between 43 and $47 \mathrm{kD}$, as previously described. ${ }^{27} \mathrm{Cx} 43^{+}$cell lines (FLB6-3 and FLB6-4) showed a level of expression of $23.7 \%$ and $9.1 \%$, respectively, as compared with Cx43 highly expressing wt FL cells (FLB6-1, Figure 3B) that was in line with the immunocytologic analysis.
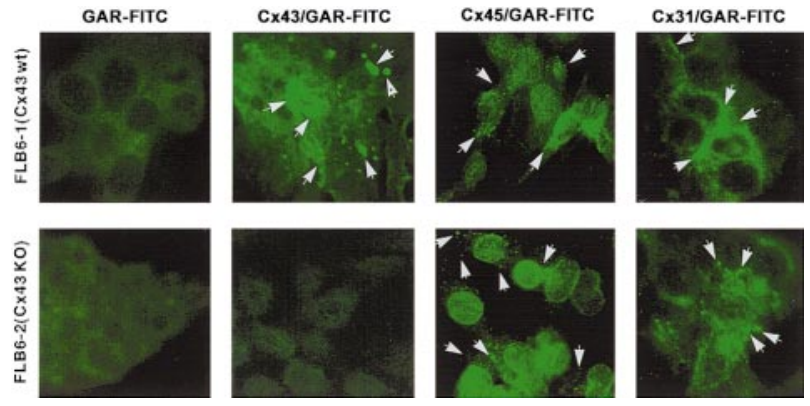

Figure 2. Cx expression assessed by immunofluorescence. $C \times 43, C x 45$, and Cx31 expression as assessed by immunofluorescence in Cx43-wt (FLB6-1) and Cx43- (FLB6-2, from Cx43-KO mice) FL cells (OM: $\times 630$ ). Note that fluorescence (arrows) is distributed in a punctate way or in thick fluorescent spots at the plasma membrane, frequently at the most distal points. Variable expression is also observed at the perinuclear area. Note that $\mathrm{C} \times 43$ and $\mathrm{C} \times 31$ expression form thicker fluorescent spots than Cx45 meanwhile. GAR-FITC, goat antirabbit FITC conjugate. See "Results" for additional description. 

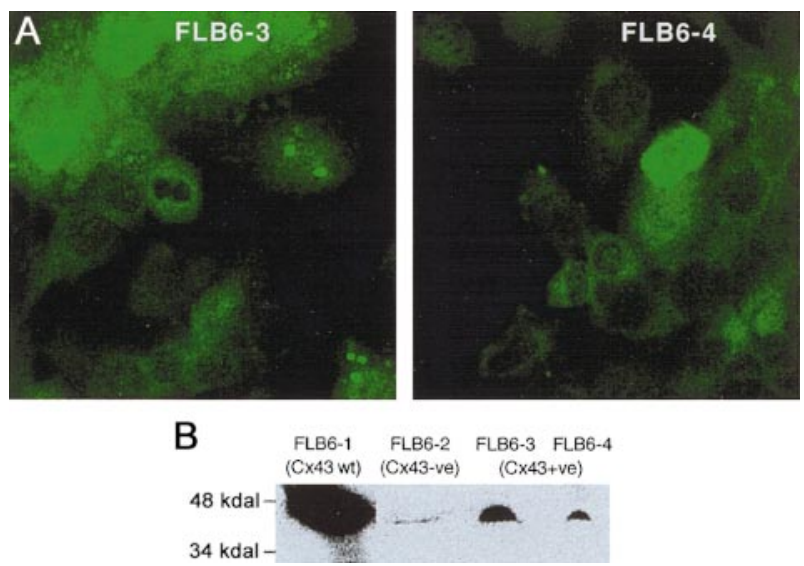

Figure 3. CX43 expression in FL stromal cells. (A) CX43 expression in the cell lines $\mathrm{Cx}_{43}^{+}$(FLB6-3 and FLB6-4, from Cx43-KO mice in which the $\mathrm{C} \times 43$ gene has been reintroduced). Note that cells show a great variance in their protein expression. Note that the fluorescence (similarly as in Cx43-wt cells, see Figure 2 ) is distributed along the membrane and the perinuclear area. (B) Western blot analysis of FL stromal cells. FLB6-1 (Cx43-wt) was chosen as Cx43-highly expressing cell line for comparison with $\mathrm{Cx} 43^{-}$cells (FLB6-2) showing some background and $\mathrm{C} \times 43^{+}$cell lines (FLB6-3 and FLB6-4, representing $23.7 \%$ and $9.1 \%$ of the band density of FLB6-1, after background subtraction-FLB6-2)

Membrane Cx45 was more homogeneously found in the cell membranes of almost all cell lines studied and usually occurred in a very punctate way with occasional brighter local fluorescent spots and medium perinuclear/nuclear intensity (Figure 2). Cx31 expression was analyzed only in FL cells, and it was more similar to that of $\mathrm{Cx} 43$ than to $\mathrm{Cx} 45$. Fluorescent patches were more frequent in membrane contact areas as compared with $\mathrm{Cx} 45$. Cx31 expression pattern, in either $\mathrm{Cx} 43$-wt or $\mathrm{Cx} 43^{-}$FL stromal cells, showed some occasional enlarged fluorescent areas and weaker cytoplasmic/ perinuclear positivity than observed for Cx45 (Figure 2).

\section{Calcein-dye transfer in BM and FL cell lines}

All wt cell lines analyzed were able to transfer calcein at a similar level (Figure 4) with NBM11F10H showing some lower IC (ie, $63 \%$ of IC as compared with FBMD-1; Figure 4). Among the FL cell lines, $\mathrm{Cx} 43^{-}$stromal cells (FLB6-2) showed $65.8 \%$ of IC events $(60.8 \%$ IC events with $<5$ cells, $33.1 \%$ IC events with 5-10 cells, and $40.0 \%$ IC events with $>10$ cells) as compared with the mean of their Cx43-wt FL counterparts (FL1E2C, FL7H7B, and FLB6-1). The reintroduction of the Cx43 gene (FLB6-3 and

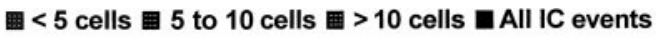

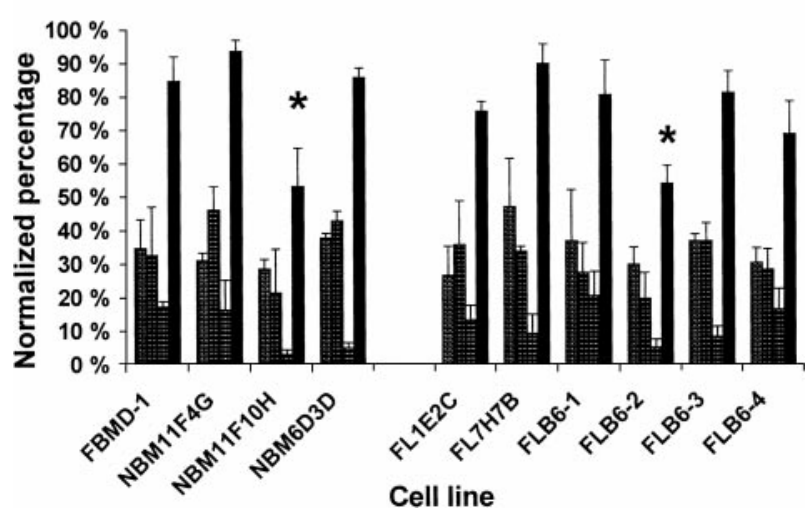

Figure 4. Homocellular calcein dye transfer in 10 different stromal cell lines from BM and FL. Two independent experiments with duplicate or triplicate wells per cell line were carried out. ${ }^{*} P<.05$, between NBM11F10H and the other BM cell lines and between the total IC level of $\mathrm{C} \times 43^{-}$(FLB6-2) and the other FL cell lines.
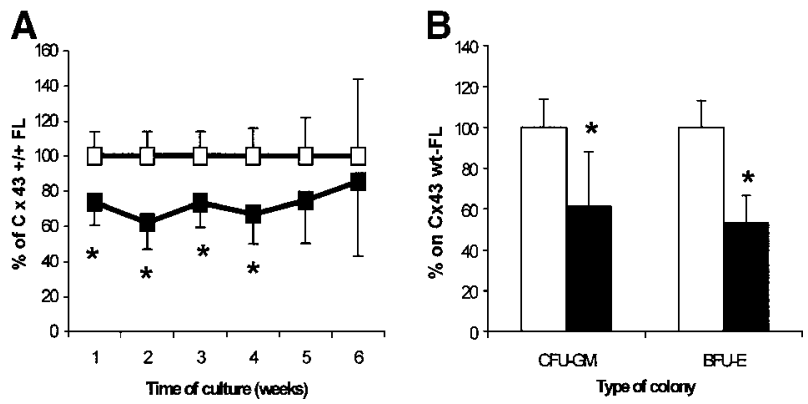

Figure 5. Analysis of hemopoietic progenitor FL content from 14.5- to 15-day FLs from Cx43-wt (empty squares and bars) and Cx43-KO (filled squares and bars). The results represent 3 independent experiments in which $\mathrm{Cx} 43-\mathrm{wt}$ ( $\mathrm{n}=11$ fetuses; median: 7) and Cx43-KO ( $\mathrm{n}=9$ fetuses; median: 3 ) FL cells had been obtained and compared within every experiment. (A) Weekly CAFC content. Actual mean numbers for weeks 1 to 6 per Cx43-wt FL were, respectively, 13738,5523 , 2648, 853, 359, and 205, and for Cx43-KO FL they were, respectively, 10 148, 3369, 2061, 591, 316, and 195. (B) Colony-forming-cell content. Actual mean numbers were 3745 CFU-GM per Cx43-wt FL and 2876 per Cx43-KO FL, and 2215 BFU-E per Cx43-wt FL and 1525 BFU-E per Cx43-KO FL. ${ }^{*} P<.05$, between progenitor content of Cx43-wt and Cx43-KO FL cells.

FLB6-4 cell lines) almost fully restored the level of IC at the different distance levels analyzed (Figure 4). The level of IC restoration was higher in the cell line FLB6-3 that expressed higher levels of $\mathrm{Cx} 43$ as indicated before.

\section{Content of CAFC and CFU in FL from Cx43-wt and Cx43-KO FL}

To investigate whether the deletion of $\mathrm{Cx} 43$ would affect the hemopoietic development in the fetuses, we analyzed the CAFC (as assayed on the FBMD-1 cell line), CFU-GM, and BFU-E FL contents. In $\mathrm{Cx} 43-\mathrm{KO}$ mice, the content of all CAFC-week type subsets was decreased as compared with wt age-matched fetuses, with significant differences found for the CAFC-week 1-4 (62\%$74 \%$ of their content in wt FLs; Figure 5A). The contents of total CFU-C and BFU-E per Cx43-KO FL were $61.3 \%$ and $53.0 \%$ of their respective content in wt FLs (Figure 5B).

\section{Effect of stromal Cx43 expression on their hemopoietic support ability}

As the reduced content of hematopoietic progenitors in the Cx43-KO FL might be due to a hemopoietic defect, or alternatively, to an indirect effect on the animal development, we analyzed whether hemopoiesis, in vitro, was similarly affected by the level of stromal $\mathrm{Cx} 43$ expression. To eliminate possible variables between stromal cell lines derived from $\mathrm{Cx} 43-\mathrm{wt}$ and $\mathrm{Cx} 43-\mathrm{KO}$ mice that might affect their hemopoietic support ability, we reintroduced the Cx43 gene (FLB6-3 and FLB6- 4 cell lines) into the $\mathrm{Cx} 43^{-}$cell line (FLB6-2). As a source of hematopoietic progenitors, we used both normal and post-5-FU murine BM cells. The CAFC-week 1 support of normal BM cells was increased 369\% in the FLB6-3 cells $(P<.05)$ as compared with the $\mathrm{Cx} 43^{-}$cell line (FLB6-2; Figure 6A). The effect of $\mathrm{Cx} 43$ expression was clearer when coculturing stromal cells with 5-FU-treated BM, which is relatively enriched for primitive hematopoietic progenitors (Figure 6B). As compared with Cx43- (FLB6-2) support, the reintroduction of $\mathrm{Cx} 43$ induced an increase of the CAFC frequency ranging from $194 \%$ (week 1) to 504\% (week 4) when assayed on FLB6-3 cells and $307 \%$ (week 3) and 254\% (week 4) when assayed on FLB6-4 cells (Figure 6B). CA support by FLB6-3 was significantly higher on weeks 1 and 2 than when assayed on FLB6-4 stromal cells. FLB6-3 cells, whose expression of $\mathrm{Cx} 43$ was 2.6-fold higher 

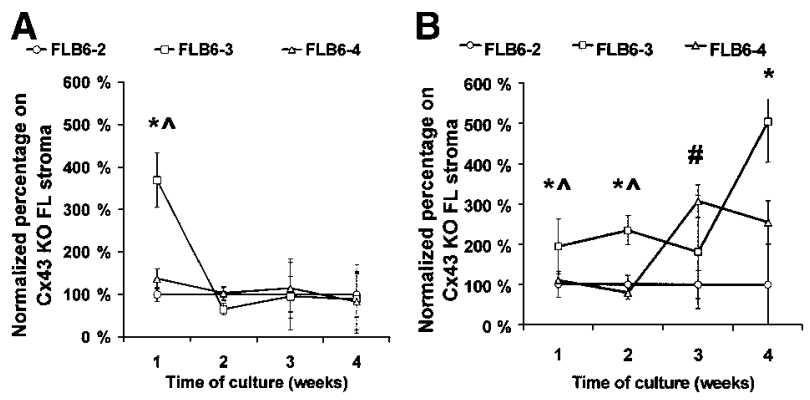

Figure 6. Frequency of various CAFC-week types after coculture with different

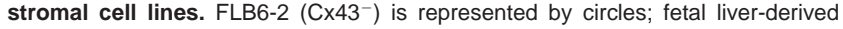
FLB6-3 $\left(\mathrm{C} \times 43^{+}\right)$, by squares and FLB6-4 $\left(\mathrm{C} \times 43^{+}\right)$, by triangles. (A) When normal mouse BM cells were used for the coculture, the mean CAFC frequencies (per $10^{5}$ cells) for weeks 1 to 4 were 36.06, 17.10, 2.10, and 1.05 (with the cell line FLB6-2); 40.0, 13.8, 1.7, and 0.8 (with the cell line FLB6-4); 61.7, 17.5, 2.8, and 1.1 (with the cell line FLB6-3). (B) When 5-FU-treated mouse BM cells were cocultured, the mean CAFC frequencies (per $10^{5}$ cells) were 29.3, 28.7, 3.1, and 0.5 (with the cell line FLB6-2); 32.7, 30.6, 9.8, and 1.3 (with the cell line FLB6-4); and 54.9, 17.1, 8.0, and 3.1 (with the cell line FLB6-3). Four experiments run in parallel were carried out for the different stromal cell lines except for the analysis of CAFC frequency of normal BM on the cell line FLB6-4 $(\mathrm{n}=2) .{ }^{*} P<.05$ between CAFC support by FLB6-2 and FLB6-3, $\# P<<.05$ between CAFC support by FLB6-2 and FLB6-4, ${ }^{\wedge} P<.05$ between CAFC support by FLB3 and FLB6-4.

than FLB6-4, supported the formation of CAs, as an average, 4.3-fold better than FLB6-4 cells when analyzed on normal BM cells and 1.75-fold better than FLB6-4 when analyzed on 5-FU-treated BM cells. These results show that the level of membrane-bound $\mathrm{Cx} 43$ expression by stromal cells may correlate with their CAFC support ability in vitro.

\section{Discussion}

The existence of GJ-like structures in hemopoietic tissues has been known for 20 years. ${ }^{28-30}$ It is known that GJ-IC can only be achieved by the expression of compatible Cxs. ${ }^{31}$ The existence of functional heteromeric channels (different Cxs within the same hemiconnexon) in different tissues ${ }^{32-34}$ and the unique ionic and size selectivities that are determined by each combination of $\mathrm{Cxs}^{35}$ make IC highly specific and regulated. Although some Cx mutations are associated with human disease ${ }^{36}$ and eight different $\mathrm{KO}$ models in rodents have been described, ${ }^{13,36-41}$ no hematological impairment has been reported related to a defect in one single $\mathrm{Cx}$ gene. We show here that various Cxs are expressed by hemopoietic tissues and that the deletion of the $\mathrm{Cx} 43$ gene leads to measurable hemopoietic defects in vivo and in vitro.

It has been reported that hemopoietic-supporting BM stromal cells express $\mathrm{Cx} 43$ but not $\mathrm{Cx} 26$ or $\mathrm{Cx} 32 .{ }^{42}$ The expression of other Cxs in them has not been studied, and, as far as we know, Cx expression in hemopoietic-supporting FL stromal cell lines has not been reported. Previous reports ${ }^{7,8}$ have suggested that $\mathrm{Cx} 43$ is solely, or predominantly, responsible for GJ-IC in stromal cells of the BM. By using a sensitive RT-PCR technique, we observed that in addition to $\mathrm{Cx} 43,4$ other Cxs are expressed in FL stromal cells (ie, $\mathrm{Cx} 30.3, \mathrm{Cx} 31, \mathrm{Cx} 31.1$, and $\mathrm{Cx} 45$ ) and 2 other Cxs in BM stromal cells (ie, Cx31 and $\mathrm{Cx} 45$ ). $\mathrm{Cx} 43$ and $\mathrm{Cx} 45$ are widespread expressed Cxs but $\mathrm{Cx} 31$ has been preferentially found in keratinocytes $^{20}$ and trophectoderm cells, ${ }^{43}$ whereas Cx30.3 and Cx31.1 have been described to be expressed in keratinocytes ${ }^{44}$ only. We show that all stromal cell lines analyzed express Cx45 mRNA, and Cx45 protein was localized at the contacting cell membrane surface. Cx31 mRNA was also expressed by almost all of the stromal cell lines, and we showed its membrane protein expression in either wt or Cx43-deficient FL stromal cells.

It has been reported that the conductance of $\mathrm{Cx} 43$-dependent GJs is much higher than that observed in $\mathrm{Cx} 45$ and other Cxs, and, therefore, negatively charged molecules could more easily pass through Cx43-dependent GJs, ${ }^{45}$ suggesting differential permeability properties among the different Cxs. Our observation that at least $3 \mathrm{Cxs}$ are expressed in BM stromal cells and at least 5 in FL stromal cells suggests that GJ-IC among stromal cells could be a complex communication system with heteromeric and heterotypic combinations between the $\mathrm{Cx}$ proteins. Heterotypic coupling (different Cxs in each hemiconnexon) between $\mathrm{Cx} 43$ and $\mathrm{Cx} 45$ has been observed in HeLa cells transfected with different mouse Cxs. The possibility that $\mathrm{Cx} 43$ and $\mathrm{Cx} 45$ may also form heterotypic junctions in stromal cells from hemopoietic organs, therefore, exists. Heterotypic coupling of $\mathrm{Cx} 31$ with either $\mathrm{Cx} 43$ or $\mathrm{Cx} 45$ probably occurs at a far lower frequency. ${ }^{35}$ The ability of $\mathrm{Cx} 30.3$ and $\mathrm{Cx} 31.1$ to form heterotypic GJs has not been described, but, if they existed, their expression would significantly increase the chance of $\mathrm{Cx}$ combinations.

The extent to which cells are functionally coupled by GJ channels depends on many different control mechanisms (gene transcription, messenger stability, translation, posttranslational modifications, topological modifications, and assembly and/or removal from the cell membrane ${ }^{46}$ ). We were interested in finding a method that showed the widest possible range of types of IC. Some dyes show different permeability, depending on the type of $\mathrm{Cx}$-forming GJs. ${ }^{35,47}$ LY dye transfer ${ }^{48}$ and transfer of loaded calcein ${ }^{18,49-51}$ techniques have been shown as methods of determining GJ-IC. LY dye transfer has been shown in osteoblasts as highly dependent on Cx43-GJ. ${ }^{10}$ In $\mathrm{Cx} 45^{+} / \mathrm{Cx} 43-\mathrm{KO}$ fetal fibroblasts that were communicating (as assessed by double whole cell patch-clamp), LY dye transfer was completely abolished, which suggests that LY is at least less transported through Cx45 GJs. ${ }^{12}$ We show that calcein dye transfer is impaired in a $\mathrm{Cx} 43$-deficient FL cell line as compared with $\mathrm{Cx} 43-\mathrm{wt}$ FL cell lines but not abolished. The reintroduction of the $\mathrm{Cx} 43$ gene allows the recovery of their lost IC ability. All of this is in agreement with our finding that other Cxs than $\mathrm{Cx} 43$ are expressed and all or some of them are involved in the IC.

A latent network of $\mathrm{Cx} 43-\mathrm{GJ}$ has been proposed in normal quiescent marrow that can be up-regulated in neonatal marrow or after forced stem cell division. ${ }^{8}$ However, it is unknown whether Cx43 gene deletion causes hemopoietic effects. Mice lacking Cx43 die between day 16 of pregnancy and birth because of a cardiac malformation at the junction between right ventricle and outflow tract, ${ }^{13,16}$ and, as an external anatomical detail, they show a swollen neck. These mice have also been described as having defects in their germ line and gonads, ${ }^{52}$ defects in neural crest cell migration, ${ }^{53}$ modifications to lenses, ${ }^{54}$ impairment of heart ventricular conduction, ${ }^{55}$ and changes in intracellular calcium concentration after neuronal mechanical stimulation. ${ }^{56}$

We describe, here, for the first time, that $\mathrm{Cx} 43$ deficiency impairs hemopoiesis. Cx43-KO day 14.5-15 fetuses have a lower content of progenitor and stem cells in their liver as compared with their wt littermates. Rather than this being an indirect effect of a possible developmental retardation, we show that this hemopoietic defect in $\mathrm{Cx} 43-\mathrm{KO}$ mice may result from an indirect effect of the $\mathrm{Cx} 43$ deletion in hemopoietic stromal cells, as we found a significant increase in the apparent CAFC outgrowth on $\mathrm{Cx} 43^{-}$stromal cell lines with a reintroduced $\mathrm{Cx} 43$ gene. We previously showed that the blockade of all GJ-IC by amphotericin B completely 
and reversibly inhibited the CA formation and hemopoiesis in stroma-contact cultures but not in stroma noncontact cultures, while also leaving the primary colony formation unaffected. ${ }^{9}$ Specifically, a dramatic increase was observed on the number of late developing CAs when 5-FU-treated BM cells were cultured on $\mathrm{Cx} 43$ reintroduced stromal cell lines. Rosendaal et al ${ }^{8}$ showed an up-regulation of Cx43-dependent GJs in 5-FU-treated BM that peaked after 4-6 days after 5-FU treatment. Our finding that day 6 post-5-FU cells showed a higher increased support for apparent CA formation on $\mathrm{Cx} 43-\mathrm{KO}$ stromal cells after the reintroduction of $\mathrm{Cx} 43$ than on $\mathrm{Cx} 43-\mathrm{KO}$ cells may support the role of $\mathrm{Cx} 43$ in regenerating $\mathrm{BM}$. A Cx31-KO model, recently described, ${ }^{36}$ may allow for the same type of studies of BM or FL stromal hemopoiesis support to analyze the independent contribution of other Cxs expressed in hemopoiesis-supporting stromal cells.

From our data, it is evident that mutual stromal cells may communicate via GJ-IC. However, it remains unclear whether stromal cells and hematopoietic (stem) cells use GJs to exchange molecules. The existence of in vitro functional GJs between stromal and BM leukocytes has been described as rare or not existing at all. ${ }^{7,42,57-59}$ We found no $\mathrm{Cx}$ expression by RT-PCR (Cx43, Cx45, or Cx31) in different sorted BM-leukocyte populations representing $\mathrm{B}$ and $\mathrm{T}$ lymphocytes, myeloid (monocyticmacrophagic and granulocytic), erythroblastic, and partly enriched hematopoietic progenitors (unpublished observations). All of these data make us believe that the $\mathrm{Cx} 43$ deficiency-related effects reported in this paper are mostly a consequence of a defect in the communication among stromal cells.

Together, these observations suggest that stromal functional Cx43-dependent GJ contribute to the stromal regulation of the clonal outgrowth of hematopoietic progenitors. It is likely that other Cxs contribute to stromal regulation of hemopoiesis, as we have previously reported that blockade of the total GJ system in stroma-supported cultures fully and reversibly blocks hemopoiesis.

\section{References}

1. Williams DA. Stem cell model of hematopoiesis. In Hoffman R, et al, eds. Hematology: Basic Principles and Practice. 2nd ed. New York, NY: Churchill Livingstone; 1995:180.

2. Long MW. Blood cell cytoadhesion molecules. Exp Hematol. 1992;20:288-301.

3. Kumar NM, Gilula NB. The gap junction communication channel. Cell. 1996;84:381-388.

4. Goodenough DA, Goliger JA, Paul DL. Connexins, connexons, and intercellular communication. Annu Rev Biochem. 1996;65:475-502.

5. Sohl G, Degen J, Teubner B, Willecke K. The murine gap junction gene connexin36 is highly expressed in mouse retina and regulated during brain development. FEBS Lett. 1998;428:27-31.

6. Spray DC. Gap junctions proteins: where they live and how they die. Circ Res. 1998;83:679681.

7. Dorshkind K, Green L, Godwin A, Fletcher WH. Connexin-43-type gap junctions mediate communication between bone marrow stromal cells. Blood. 1993;82:38-45.

8. Rosendaal M, Green CR, Rahman A, Morgan D. Up-regulation of the connexin $43^{+}$gap junction network in haemopoietic tissue before the growth of stem cells. J Cell Sci. 1994;107:29-37.

9. Rosendaal M, Mayen A, de Koning A, DuninaBarkovskaya T, Krenacs T, Ploemacher R. Does transmembrane communication through gap junctions enable stem cells to overcome stromal inhibition? Leukemia. 1997;11:1281-1289.

10. Steinberg TH, Civitelli R, Geist ST, et al. Connexin43 and connexin45 form gap junctions with different molecular permeabilities in osteoblastic cells. EMBO J. 1994;13:744-750.

11. Koval M, Geist ST, Westphale EM, et al. Transfected connexin45 alters gap junction permeability in cells expressing endogenous connexin43. J Cell Biol. 1995;130:987-995.

12. Martyn KD, Kurata WE, Warn-Cramer BJ, Burt JM, TenBroek E, Lau AF. Immortalized connexin43 knockout cell lines display a subset of biological properties associated with the transformed phenotype. Cell Growth Differ. 1997;8: 1015-1027.

13. Reaume AG, de Sousa PA, Kulkarni S, et al. Cardiac malformation in neonatal mice lacking connexin 43. Science. 1995;267:1831-1834.

14. Slieker WA, van der Loo JC, de Rijk-de Bruijn MF, Godrey DI, Leenen PJM, van Ewijk W. ER-MP12 antigen, a new cell surface marker on mouse bone marrow cells with thymus-repopulating ability. II. Thymus-homing ability and phenotypic characterization of ER-MP12-positive bone marrow cells. Int Immunol. 1993:5:1099-1107.

15. Breems DA, Blokland EA, Neben S, Ploemacher $R E$. Frequency analysis of human primitive haematopoietic stem cell subsets using a cobblestone area forming cell assay. Leukemia. 1994;8: 1095-1104.

16. Ya J, Erdtsieck-Ernste EB, de Boer PA, et al. Heart defects in connexin43-deficient mice. Circ Res. 1998;82:360-366.

17. Beyer EC, Paul DL, Goodenough DA. Connexin43: a protein from rat heart homologous to a gap junction protein from liver. J Cell Biol. 1987; 105:2621-2629.

18. Ziambaras K, Lecanda F, Steinberg TH, Civitelli R. Cyclic stretch enhances gap junctional communication between osteoblastic cells. J Bone Miner Res. 1998;13:218-228.

19. Hennemann H, Schwarz HJ, Willecke K. Characterization of gap junction genes expressed in $\mathrm{F9}$ embryonic carcinoma cells: molecular cloning of mouse connexin31 and -45 cDNAs. Eur J Cell Biol. 1992;57:51-58.

20. Butterweck A, Elfgang C, Willecke K, Traub O Differential expression of the gap junction proteins connexin45, $-43,-40,-31$, and -26 in mouse skin. Eur J Cell Biol. 1994;65:152-163.

21. Sambrook J, Fritsch EF, Maniatis T. Molecular Cloning. A Laboratory Manual. 2nd edition. Plainview, N Y: Cold Spring Harbor Laboratory Press; 1989.

22. Fiorenza MT, Mangia F. Quantitative RT-PCR amplification of RNA in single mouse oocytes and preimplantation embryos. Biotechniques. 1998; 24:618-623.

23. Davies TC, Barr KJ, Jones DH, Zhu D, Kidder GM. Multiple members of the connexin gene family participate in preimplantation development of the mouse. Dev Genet. 1996;18:234-243.

24. Ploemacher RE, van der Sluijs JP, Voerman JS, Brons $\mathrm{NH}$. An in vitro limiting-dilution assay of long-term repopulating hematopoietic stem cells in the mouse. Blood. 1989;74:2755-2763.

25. Umezawa A, Harigaya K, Abe H, Watanabe Y. Gap-junctional communication of bone marrow stromal cells is resistant to irradiation in vitro. Exp Hematol. 1990;18:1002-1007.

26. Ploemacher RE, van der Sluijs JP, van Beurden CA, Baert MR, Chan PL. Use of limiting-dilution type long-term marrow cultures in frequency analysis of marrow-repopulating and spleen colony-forming hematopoietic stem cells in the mouse. Blood. 1991;78:2527-2533.

27. Crow DS, Beuer EC, Paul DL, Kobe SS, Lau AF.
Phosphorylation of connexin 43 gap junction protein in uninfected and Rous sarcoma virus-transformed mammalian fibroblasts. Mol Cell Biol. 1990;10:1754-1763.

28. Campbell FR. Gap junctions between cells of bone marrow: an ultrastructural study using tannic acid. Anat Rec. 1980;196:101-107.

29. Yamazaki K. SI/SId mice have an increased number of gap junctions in their bone marrow stromal cells. Blood Cells. 1988;13:421-435.

30. Yamazaki K, Zacharov Y, Simmons PJ, Dexter TM, Allen TD. A comparative morphometric study on the ultrastructure of adherent cells in longterm bone marrow culture from normal and congenitally anemic mice. Blood Cells. 1989;15:343364.

31. White TW, Paul DL, Goodenough DA, Bruzzone R. Functional analysis of selective interactions among rodent connexins. Mol Biol Cell. 1995;6: 459-470.

32. Jiang JX, Goodenough DA. Heteromeric connexons in lens gap junction channels. Proc Natl Acad Sci U S A. 1996;93:1287-1291.

33. He DS, Jiang JX, Taffet SM, Burt JM. Formation of heteromeric gap junction channels by connexins 40 and 43 in vascular smooth muscle cells. Proc Natl Acad Sci U S A. 1999;96:6495-6500.

34. Stauffer KA. The gap junction proteins beta 1-connexin (connexin-32) and beta 2-connexin (connexin-26) can form heteromeric hemichannels. J Biol Chem. 1995;270:6768-6772.

35. Elfgang $\mathrm{C}$, Eckert R, Lichtenberg-Frate $\mathrm{H}$, et al. Specific permeability and selective formation of gap junction channels in connexin-transfected HeLa cells. J Cell Biol. 1995;129:805-817.

36. Willecke K, Kirchhoff S, Plum A, Temme A, Thonnissen E, Ott T. Biological functions of connexin genes revealed by human genetic defects, dominant negative approaches and targeted deletions in the mouse. Novartis Found Symp. 1999;219: 76-88.

37. Simon AM, Goodenough DA, Li E, Paul DL. Female infertility in mice lacking connexin $37 . \mathrm{Na}-$ ture. 1997;385:525-529.

38. Kirchhoff S, Nelles E, Hagendorff A, Kruger O, Traub O, Willecke K. Reduced cardiac conduction velocity and predisposition to arrhythmias in connexin40-deficient mice. Curr Biol. 1998;8:299302.

39. Nelles E, Butzler C, Jung D, et al. Defective propagation of signals generated by sympathetic nerve stimulation in the liver of connexin32-deficient mice. Proc Natl Acad Sci U S A. 1996;93: 9565-9570. 
40. Gabriel HD, Jung D, Butzler C, et al. Transplacental uptake of glucose is decreased in embryonic lethal connexin26-deficient mice. J Cell Biol. 1998;140:1453-1461.

41. Simon AM, Goodenough DA. Diverse functions of vertebrate gap junctions. Trends Cell Biol. 1988; 8:477-483.

42. Krenacs $\mathrm{T}$, Rosendaal M. Connexin 43 gap junc tions in normal, regenerating and culture mouse bone marrow and in human leukemias. Am J Pathol. 1998;152:993-1004.

43. Dahl E, Winterhager E, Reuss B, Traub O, Butterweck A, Willecke K. Expression of the gap junction proteins connexin31 and connexin43 correlates with communication compartments in extraembryonic tissues and in the gastrulating mouse embryo, respectively. J Cell Sci. 1996; 109:191-197.

44. Hennemann $\mathrm{H}$, Dahl E, White JB, et al. Two gap junction genes, connexin 31.1 and 30.3 , are closely linked on mouse chromosome 4 and preferentially expressed in skin. J Biol Chem. 1992; 267:17225-17233.

45. Veenstra RD. Size and selectivity of gap junction channels formed from different connexins. J Bioenerg Biomembr. 1996;28:327-337.
46. Yeager M, Gilula NB. Membrane topology and quaternary structure of cardiac gap junction ion channels. J Mol Biol. 1992;223:929-948.

47. Kwak BR, Jongsma HJ. Selective inhibition of gap junction channel activity by synthetic peptides. J Physiol. 1999;516:679-685.

48. Stewart WW. Functional connections between cells as revealed by dye-coupling with a highly fluorescent naphthalimide tracer. Cell. 1978;14: 741-759.

49. Lecanda F, Towler DA, Ziambaras K, et al. Gap junctional communication modulates gene expression in osteoblastic cells. Mol Biol Cell. 1998; 9:2249-2258

50. Frenzel EM, Johnson RG. Gap junction formation between cultured embryonic lens cells is inhibited by antibody to N-cadherin. Dev Biol. 1996;179:1-16.

51. Tomasetto C, Neveu MJ, Daley J, Horan PK, Sager R. Specificity of gap junction communication among human mammary cells and connexin transfectants in culture. J Cell Biol. 1993;122:157-167.

52. Juneja SC, Barr KJ, Enders GC, Kidder GM. Defects in the germ line and gonads of mice lacking connexin 43. Biol Reprod. 1999;60:1263-1270.

53. Huang GY, Cooper ES, Waldo K, Kirby ML, Gilula NB, Lo CW. Gap junction-mediated cell-cell com- munication modulates mouse neural crest migration. J Cell Biol. 1998;143:1725-1734

54. Gao Y, Spray DC. Structural changes in lenses of mice lacking the gap junction protein connexin43. Invest Ophtalmol Vis Sci. 1998;39:1198-1209.

55. Thomas SA, Schuessler RB, Berul Cl, et al. Disparate effects of deficient expression of connexin43 on atrial and ventricular conduction: evidence for chamber-specific molecular determinants of conduction. Circulation. 1998;97:686-691.

56. Naus CC, Bechberger JF, Zhang Y, et al. Altered gap junctional communication, intercellular signaling, and growth in cultured astrocytes deficient in connexin43. J Neurosci Res. 1997;49:528-540.

57. Alves LA, de Carvalho AC, Savino W. Gap junctions: a novel route for direct cell-cell communication in the immune system? Immunol Today. 1998;19:269-275.

58. Alves LA, Coutinho-Silva R, Persechini PM Spray DC, Savino W, Campos de Carvalho AC. Are there functional gap junctions or junctional hemichannels in macrophages? Blood. 1996;88: 328-334.

59. Rosendaal M, Gregan A, Green CR. Direct cellcell communication in the blood-forming system. Tissue Cell. 1991;23:457-470. 